\title{
Newly Food-Insecure College Students in Appalachia During the COVID-19 Pandemic
}

\author{
Rebecca L. Hagedorn, PhD, RDN; Ayron E. Walker, MS; Rachel A. Wattick, MS; \\ Melissa D. Olfert, DrPH, RDN
}

\begin{abstract}
Objective: This study investigated if the coronavirus disease (COVID-19) pandemic influenced college student food insecurity and factors that might contribute to a student becoming newly food insecure.

Design: A convenience sample was assessed using a cross-sectional survey.

Setting: Online.

Participants: College students $(n=2,018)$ enrolled at a land-grant institution in Appalachia.

Main Outcome Measure(s): Food insecurity was assessed using the Hunger Vital Sign with reference before COVID-19 and since COVID-19. Demographic and pandemic-specific questions and their associations with food insecurity status were assessed.

Analysis: Students were categorized as food secure (food secure before and since COVID-19 or food insecure in the year before COVID-19 but not food insecure since COVID-19), consistently food insecure (food insecure before and since COVID-19), and newly food insecure (food secure before but food insecure since COVID-19). Multivariate logistic regression was used to investigate the relationship between new food insecurity and contributing factors.

Results: Of respondents, $68.4 \%$ were food secure, $16.5 \%$ were consistently food insecure, and $15.1 \%$ were newly food insecure. Loss of employment, increased grocery expenditure, anxiety, and a perceived threat posed by COVID-19 were significant indicators of students being newly food insecure.

Conclusions and Implications: More students were facing food insecurity as a result of the COVID-19 pandemic. Continued advocacy for sustainable solutions to college food insecurity is needed.
\end{abstract}

Key Words: college, university, food insecurity, COVID-19, pandemic (J Nutr Educ Behav. 2022;54:202-210.)

Accepted August 15, 2021. Published online November 10, 2021.

\section{INTRODUCTION}

Food insecurity-defined as the lack of consistent access to enough food to live an active and healthy lifestyle ${ }^{1}$ or the limited or uncertain availability of nutritionally adequate, safe foods obtained in socially acceptable ways ${ }^{2}$-has been impacted during the coronavirus disease (COVID-19) pandemic because of food shortages, increase cost of food, and loss of income. ${ }^{3}$ Since the declaration of the COVID-19 pandemic by the World
Health Organization in March, 2020 and the implementation of social distancing practices to flatten the curve, ${ }^{4}$ household food insecurity is reported to have increased. ${ }^{5,6}$ With the rise in unemployment rates ${ }^{7}$ and increased need for governmental benefits, which tracks similar to the Great Depression ${ }^{8}$ and the 2007 -2008 recession, there is an increased risk of food insecurity and hunger. ${ }^{9}$ However, food insecurity is not only impacted by the ability to afford food but by food accessibility

Division of Animal and Nutritional Sciences, Davis College of Agriculture, Natural Resources, and Design, West Virginia University, Morgantown, WV

Conflict of Interest Disclosure: The authors have not stated any conflicts of interest.

Address for correspondence: Melissa D. Olfert, DrPH, RDN, Division of Animal and Nutritional Sciences, School of Agriculture, Davis College of Agriculture, Natural Resources and Design, West Virginia University, 1194 Evansdale Drive, G25 Agriculture Sciences Building, Morgantown, WV 26506; E-mail: melissa.olfert@mail.wvu.edu

(C) 2021 Society for Nutrition Education and Behavior. Published by Elsevier Inc. All rights reserved.

and availability and monetary stability. ${ }^{10}$ The COVID-19 pandemic influenced many aspects of the food system that impact food accessibility and availability, including production, transportation, food costs, and shortages. ${ }^{5}$ With the changes to the food system during COVID-19 $9^{5,11,12}$ and the known detrimental impacts on the health and well-being of populations, ${ }^{13-17}$ it is imperative to understand the risk of food insecurity among different populations in an attempt to prevent food insecurity from continuing to rise.

Research suggests that food insecurity rates among college students surpass the national household average with a weighted estimate of $37 \% .{ }^{18}$ Food-insecure students struggle to maintain grade point average and academics requirements, have poor health outcomes, experience increased stress and anxiety, and grapple with managing money expenditure. ${ }^{19-24}$ In response to 
stress-inducing situations, many students develop behavioral patterns to cope, including changing their eating patterns, borrowing money, or postponing bill payments. ${ }^{19,20}$ These coping mechanisms are similar to food-insecure and newly food-insecure behaviors during the COVID-19 pandemic. $^{5}$ With the suggested increased risk of food insecurity and its associations during the COVID-19 pandemic and the higher rates of food insecurity among college students, it is pertinent to study the possible impacts of the pandemic on college students' food security status.

Therefore, although research has shown college students to be susceptible to food insecurity, the COVID-19 pandemic adds another layer of burden on this population. Most college campuses provide students access to food (dining halls) and food assistance resources (food pantries), but COVID-19 restrictions limited students' ability to use campus resources. $^{25}$ College students report their ability to work during the COVID-19 pandemic was impacted by job loss or cut hours, resulting in already financially limited students being without income to support their basic needs. ${ }^{26}$ Furthermore, many were forced to move out of college towns and back to their hometowns, where job opportunities may have been even more scarce. ${ }^{26}$ Unlike most of the American population, which received federal stimulus checks to offset the financial burdens of the COVID-19 pandemic, a majority of college students were ineligible because of claimed dependence status. ${ }^{25}$ Therefore, with the cost of goods increased, access to campus resources limited, and the financial opportunities for college students narrowed, the COVID-19 pandemic heightened a student's risk of food insecurity. To date, limited research has evaluated food insecurity among college students and investigated factors that may have contributed to the onset of food insecurity during the COVID-19 pandemic. $^{25,27,28}$ This current study aimed to investigate if students became food insecure since the COVID-19 pandemic and factors related to a student becoming food insecure during the pandemic at an Appalachian university.

\section{METHODS}

This study was approved by the Institutional Review Board (no. 2003924134) at West Virginia University. This cross-sectional, online study was conducted between late March and early April, 2020, at which time courses were fully online and campus services were limited. To be eligible, students had to be currently enrolled at the university and aged $\geq 18$ years. Students were recruited using the university listserv $(\mathrm{N}=39,903)$, with an initial email sent in early March containing a link to complete a Qualtrics survey (Qualtrics XM, 2021). Three reminder emails were sent 4,18 , and 25 days later to students who had not completed the survey as recommended by Dillman's Tailored Design Methods for the implementation of surveys. ${ }^{29}$ Before accessing the survey, students were required to read and accept the informed consent. Students who completed the survey were given the opportunity to provide their email for a chance to win 1 of 6 gift cards, each valued at $\$ 100$. Email information was entered on a separate Qualtrics link to ensure confidentiality.

\section{Survey Design}

A 161-item survey was developed by researchers to assess various aspects of health and well-being during the pandemic (Supplementary Data). The full survey took approximately 40-60 minutes to complete. Variables of interest in this study were guided by previous college food insecurity literature. ${ }^{30}$

\section{Demographics and Pandemic Changes}

The survey asked students to self-report their race and ethnicity, ${ }^{31,32}$ year in school, ${ }^{20,21}$ gender identity, ${ }^{33}$ disability status, $^{30}$ if they had dependents, ${ }^{19,34}$ current employment status, $^{35}$ if they were from the Appalachian region, ${ }^{19,21}$ and if they were a first-generation student. ${ }^{30}$ Race was selected from a list that included White, Black, American Indian or Alaska Native, Asian, Native Hawaiian or Pacific Islander, and other. Students were able to select all that applied.
Students were asked about changes to their lives since the COVID-19 pandemic. These questions included if they had lost employment, had dropped any of their college courses and had lost access to food resources since the start of the COVID-19 pandemic. The survey asked if students had a meal plan and ate on campus before the COVID-19 pandemic, if they have struggled to have meals without access to campus dining and whether they had children or other dependents. Access to the adequate food supply in the grocery store was also assessed. Changes in student's meal intake were measured by asking, "Compared to before COVID-19, are you eating less, more, or the same?" and "Since COVID-19, has your cooking increased, decreased, or stayed the same?" Student expenditures were assessed by asking if spending on food and alcohol had increased, decreased, or stayed the same since the pandemic. Finally, students were asked the level of threat they perceived the COIVD-19 pandemic to be for themselves on a scale of not a threat at all, a slight threat, a significant threat, or a very severe threat.

\section{Depression}

Depression was measured using the Patient Health Questionnaire-9 Item. ${ }^{36}$ The Patient Health Questionnaire-9 Item is a validated tool that asks respondents a series of questions on the experience of depressive symptoms over the past 2 weeks. ${ }^{36}$ Symptoms included problems such as little interest or pleasure in doing things with response options of not at all, several days, more than half the days, and nearly every day. Responses are summed for a total possible score of 27 , with cutoffs of minimal depression (0-4), mild depression (5-9), moderate depression (10-14), moderately severe depression (15-19), and severe depression (20-27).

\section{Anxiety}

Anxiety was measured using the Generalized Anxiety Disorder-7 Item, ${ }^{37}$ a validated tool widely used to measure an individual's presence of anxiety through the collection of responses to 7 questions about the experience 
of symptoms such as feeling nervous, anxious, or on edge. Response options include not at all, several days, more than half the days, and nearly every day. Scores are summed for a possible score of 21 with cutoffs of minimal anxiety (0-4), mild anxiety (5-9), moderate anxiety (10-14), and severe anxiety (15-21).

\section{Food Insecurity}

Food insecurity was assessed using the Hunger Vital Sign, a tool derived from the US Department of Agriculture Household Food Security Survey Module ${ }^{38}$ and validated as a screening tool in a pediatric population by $\mathrm{Ha}$ ger and colleagues. ${ }^{39}$ This screener has been used in previous college food insecurity work. ${ }^{40}$ This 2-item screener was modified to assess before and since the COVID-19 pandemic. Thus, the survey was asked twice for a total of 4 questions. The first questions asked, "Before the COVID-19 pandemic, did you worry whether your food would run out before you got money to buy more?" and "Before the COVID-19 pandemic, the food you bought just didn't last and you didn't have money to get more." Affirmation of often true or sometimes true (vs never true) to either or both of the statements indicated a student was at risk for food insecurity. The questions were asked again with "Since the COVID-19 pandemic" substituted for "Before the COVID-19 pandemic."

\section{Analysis}

The survey was initiated by 2,764 students, but only participants who completed the food insecurity questions, and $50 \%$ or more of the remaining survey, were included in the analysis. The resulting sample for analysis was 2,018 students. Because of limited response in some groups, to avoid potential identification of respondents, researchers collapsed race into White, Black, Asian, Bi/ Mixed, and other before analysis.

Researchers followed the methodology of a previous COVID-19 food insecurity study and created 3 categories of food security status. ${ }^{5}$ These included: food-secure students (students who were food secure before and since COVID-19 and students who were food insecure at some point before COVID-19 but were no longer food insecure since the COVID-19 pandemic), consistently food-insecure students (students who were both food insecure before COVID-19 and remained food insecure since the COVID-19 pandemic), and newly food-insecure students (students who were food secure before the COVID-19 pandemic but food insecure since COVID-19).

To determine associations among collected variables and the food security categories, the Pearson chisquare test was used. Significant variables were entered into a forward selection logistic regression model to determine which factors are correlated with a student being newly food insecure during the COVID-19 pandemic. The selection criterion for the model entry was $P<0.05$. The forward selection was used $^{41}$; thus, each variable was added independently, with nonsignificant variables being dropped from the model with only significant variables remaining in the final model. Results are presented in odds ratio and confidence intervals. Data were analyzed using JMP Pro (version 12.2, SAS Inc, 2012) and SAS (version 9.4, SAS Inc, 2013).

\section{RESULTS}

Survey results were available for 2,018 students (5.1\% response rate). The mean age of the sample was 24.9 \pm 5.54 years, and $29.6 \%$ were in graduate/professional school. The majority $(70.7 \%)$ were female, White $(83.0 \%)$, were not first-generation college students (71.5\%), and did not identify as Appalachian (53.2\%). Of the sample of students, $68.4 \%$ were food secure, $16.5 \%$ were consistently food insecure, and $15.1 \%$ were newly food insecure. Thus, $31.6 \%$ of the student sample were food insecure at the time of the study. Characteristics by food security status are presented in Table 1 . Newly food-insecure students $(68.1 \%)$ were more likely to report they had lost employment because of COVID-19 compared with consistently food-insecure (62.7\%) and food-secure $(40.6 \%)$ students $(P$ $<0.001)$. More newly food-insecure students $(9.4 \%)$ reported they lost access to food resources compared with consistently food-insecure $(8.6 \%)$ and food-secure (2.0\%) students $(P<0.001)$. Students who were newly food insecure $(50.9 \%)$ had higher reports of their expenditures on groceries increasing since COVID19 than consistently food-insecure (43.7\%) and food-secure (34.6\%) students $(P<0.001)$. Furthermore, newly food-insecure students (14.0\%) were more likely to perceive COVID-19 as a severe threat than consistently food-insecure (10.1\%) and food-secure $(4.5 \%)$ students $(P<$ $0.001)$. Newly food-insecure $(24.5 \%)$ students were more likely to have relied on a campus meal plan before COVID-19 than consistently foodinsecure $\quad(38.2 \%) \quad$ students $(P=0.0103)$. Newly (9.7\%) and consistently $(10.6 \%)$ food-insecure students were more likely to report they had a disability than food-secure (5.2\%) students $(P<0.001)$. More newly $(41.0 \%)$ and consistently $(37.6 \%)$ food-insecure students reported being first-generation students than food-secure (23.7\%) students $(P<0.001)$. Students who self-reported severe levels of anxiety and depression were more likely to be newly $(32.1 \%$ and $16.7 \%)$ and consistently $\quad(30.6 \%$ and $26.1 \%)$ food-insecure than food-secure $(16.5$ and 8.6\%) students $(P<0.001$, respectively). Newly (45.7\%) and consistently (46.5) food-insecure students were more likely to report they were eating less since COVID-19 $(P<$ $0.001)$ than food-secure $(31.0 \%)$ students.

Once entered into the forward selection logistic regression, loss of employment, grocery expenditure, anxiety, and the perceived threat posed by COVID-19 remained significant indicators of students being newly food insecure, as reported in Table 2. In fact, students who lost employment as a result of COVID-19 were $130 \%$ more likely to be food insecure than students who were consistently food insecure or food secure. Students were 58\% more likely to be newly food insecure if they had increased grocery expenditure since COVID-19. College students who reported severe levels of anxiety were 59\% more likely to be newly food insecure than students 
Table 1. Respondent Characteristics For Food-Secure, Consistently Food-Insecure, and Newly Food-Insecure College Students

\section{Variable}

Gender identity

Male

Female

Transgender

Nonbinary or other

Race

White

Black

Asian

Bi/Mixed

Other

School year

Freshman

Sophomore

Junior

Senior

Graduate

First-generation college student

No

Yes

Appalachian

No

Yes

Disability status

No

Yes

Has dependents

No

Yes

Lost employment since COVID-19

No

Yes

Lost food resources since COVID-19

No

Yes

Had campus meal plan before COVID-19

No

Yes

Change in eating amount since COVID-19

Eating less

Eating the same amount

Eating more

Change in cooking amount since COVID-19

Cooking less

Cooking the same amount

Cooking more

Change in grocery expenditure since COVID-19

Decreased

Stayed the same

Increased

Perceived COVID-19 threat

Not a threat at all

A slight threat

\section{Food-Secure Students}

$$
\begin{gathered}
364(26.9) \\
960(71.0) \\
20(1.5) \\
8(0.6)
\end{gathered}
$$

$1124(83.2)$

$29(2.2)$

$54(4.0)$

79 (5.8)

$65(4.8)$

$233(17.2)$

215 (15.9)

$220(16.2)$

$257(19.0)$

430 (31.7)

1036 (76.3)

$321(23.7)$

716 (52.8)

$639(47.2)$

1283 (94.7)

$71(5.2)$

1301 (95.7)

58 (4.3)

387 (59.4)

265 (40.6)

1323 (98.0)

27 (2.0)

1003 (74.6)

341 (25.4)

421 (31.0)

330 (24.3)

609 (44.8)

773 (76.0)

349 (26.2)

211 (15.8)

318 (24.3)

$539(41.1)$

454 (34.6)

318 (23.7)

739 (55.1)

\section{Consistently \\ Food-Insecure \\ Students}

92 (28.2)

$232(71.2)$

0 (0)

$2(0.6)$

256 (78.5)

$13(4.0)$

$9(2.8)$

$19(5.8)$

$29(8.9)$

37 (11.4)

$47(14.4)$

$81(24.9)$

94 (28.8)

67 (20.5)

204 (62.4)

$123(37.6)$

$174(53.4)$

$152(46.6)$

288 (89.4)

34 (10.6)

$311(95.1)$

$16(4.9)$

75 (37.3)

$126(62.7)$

296 (91.4)

28 (8.6)

266 (82.6)

$56(17.4)$

$152(46.5)$

50 (15.3)

125 (38.2)

181 (57.6)

79 (25.2)

54 (17.2)

72 (22.6)

107 (33.6)

139 (43.7)

52 (16.3)

$152(47.8)$
Newly

Food-Insecure

Students

89 (30.0)

203 (68.3)

$2(0.7)$

3 (1.0)

240 (80.8)

$12(4.0)$

13 (4.4)

$16(5.4)$

$16(5.4)$

0.27

34 (11.3)

46 (15.4)

61 (20.3)

69 (23.0)

$90(30.0)$

177 (59.0)

$123(41.0)$

$160(53.7)$

138 (46.3)

270 (90.3)

29 (9.7)

278 (92.7)

22 (7.3)

59 (31.9)

126 (68.1)

269 (90.6)

$28(9.4)$

$222(75.5)$

72 (24.5)

137 (45.7)

42 (14.0)

121 (40.3)

193 (66.8)

56 (19.4)

40 (13.8)

52 (18.0)

$90(31.1)$

147 (50.9)

$<0.001$

0.96

$<0.001$

0.081

$<0.001$

$<0.001$

0.01

$<0.001$

0.07

55 (18.8)

133 (45.4) 


\begin{tabular}{|c|c|c|c|c|}
\hline Variable & $\begin{array}{l}\text { Food-Secure } \\
\text { Students }\end{array}$ & $\begin{array}{l}\text { Consistently } \\
\text { Food-Insecure } \\
\text { Students }\end{array}$ & $\begin{array}{l}\text { Newly } \\
\text { Food-Insecure } \\
\text { Students }\end{array}$ & $\boldsymbol{P}$ \\
\hline A significant threat & $224(16.7)$ & $82(25.8)$ & $64(21.8)$ & \\
\hline A very severe threat & $60(4.5)$ & $32(10.1)$ & $41(14.0)$ & \\
\hline \multicolumn{5}{|l|}{ PHQ-9 Depression Scale } \\
\hline Minimal (0-4) & $311(22.9)$ & $23(7.1)$ & $31(10.4)$ & $<0.001$ \\
\hline Mild (5-9) & $408(30.0)$ & $56(17.2)$ & $68(22.7)$ & \\
\hline Moderate (10-14) & $309(22.7)$ & $70(21.5)$ & $94(31.4)$ & \\
\hline Moderately severe (15-19) & $215(15.8)$ & $92(28.2)$ & $56(18.7)$ & \\
\hline Severe $(20-27)$ & $117(8.6)$ & $85(26.1)$ & $50(16.7)$ & \\
\hline GAD-7 Anxiety Scale & & & & $<0.001$ \\
\hline Minimal (0-4) & $431(31.7)$ & $49(15.0)$ & $51(17.1)$ & \\
\hline Mild (5-9) & $436(32.1)$ & $69(21.2)$ & $85(28.4)$ & \\
\hline Moderate (10-14) & $269(19.8)$ & $67(20.6)$ & $67(22.4)$ & \\
\hline Severe (15-21) & $224(16.5)$ & $141(30.6)$ & $96(32.1)$ & \\
\hline
\end{tabular}

COVID-19 indicates coronavirus disease 2019; GAD-7, Generalized Anxiety Disorder-7 Item; PHQ-9, Patient Health Questionnaire-9 Item.

Note: Values are n (\%). Significant associations were represented by $P<0.05$ from chi-square test of independence analysis; PHQ-9 assesses the number of depressive symptoms in the past 2 weeks; GAD-7 assesses an individual's presence of anxiety during the past 2 weeks.

who reported minimal anxiety. Finally, students who perceived COVID-19 as a severe threat to themselves were $120 \%$ more likely to be newly food insecure than students who were consistently food insecure or food secure.

\section{DISCUSSION}

This study aimed to investigate if changes related to the COVID-19 were related to a change in food security status among college students. This study adds to the research on the high prevalence of food insecurity among college students, ${ }^{18}$ with $31.6 \%$ of the sample classified as food insecure. However, in light of the COVID-19 pandemic, students who were previously food secure potentially faced new burdens that

Table 2. Logistic Regression Model Predicting New Food Insecurity Among University Students

$\begin{array}{llll}\text { Variable } & \text { Levels } & \text { Odds Ratio } & \text { 95\% Confidence Interval } \\ \text { Lost employment since COVID-19 } & \text { No } & 1(\mathrm{REF}) & 1(\mathrm{REF}) \\ & \text { Yes } & 2.30 & 1.61-3.29 \\ \text { Change in grocery expenditure since COVID-19 } & \text { Stayed the same } & 1(\mathrm{REF}) & 1 \text { (REF) } \\ & \text { Increased } & 1.58 & 0.56-2.35 \\ & \text { Decreased } & 0.88 & 1.45 \\ \text { GAD-7 Anxiety Scale } & \text { Minimal (0-4) } & 1 \text { (REF) } & 0.47-1.32 \\ & \text { Mild (5-9) } & 0.79 & 0.60-1.64 \\ & \text { Moderate (10-14) } & 0.99 & 1.01-2.49 \\ \text { Perceived COVID-19 threat } & \text { Severe (15-21) } & 1.59 & 1 \text { (REF) } \\ & \text { Not a threat at all } & 1 \text { (REF) } & 0.61-1.55 \\ & \text { A slight threat } & 0.98 & 0.58-1.84 \\ & \text { A significant threat } & 1.03 & 1.16-4.16\end{array}$

COVID-19 indicates coronavirus disease 2019; GAD-7, Generalized Anxiety Disorder-7 Item; PHQ-9, Patient Health Questionnaire-9 Item; REF, reference.

Note: The logistic regression model reports the odds of being newly food insecure than both food-secure and consistently foodinsecure students combined. The selection criteria for the model entry was $P<0.05$. Variables from simple analyses were entered into a forward selection multiple logistic regression model. Variables were added in the following order: school year, first-generation college student, disability status, lost employment since COVID-19, had campus meal plan before COVID-19, lost food resources since COVID-19, change in eating amount since COVID-19, change in cooking amount since COVID-19, change in grocery expenditure since COVID-19, perceived COVID-19 threat, PHQ-9 depression scale, and GAD-7 anxiety scale. Only variables that remained significant in the model are shown. 
contribute to food insecurity. ${ }^{25,27,28}$ In fact, this study identified $15 \%$ of students being newly food insecure since the COVID-19 pandemic. Factors that influenced the odds of new food insecurity included: loss of employment, increased grocery expenditure, and the perceived threat of COVID-19.

Since the beginning of the COVID19 pandemic, rates of unemployment and food insecurity rose nationally. The highest unemployment rates during the pandemic are noted among adults aged 18-24 years, including much of the college population. ${ }^{7,42}$ This loss of employment is detrimental to college students, evidenced by students who faced the loss of employment being 130\% more likely to be newly food insecure. This finding is consistent with research by Owens and colleagues, ${ }^{25}$ which found the strongest predictors of student food insecurity during the pandemic were loss of employment and being furloughed. Furthermore, loss of employment, at both the personal and household level, was associated with higher odds of food security status changes. ${ }^{27}$ However, the \#RealCollege Report, conducted by the Hope Center, found that students who experienced no change in employment also experienced food and housing insecurity. ${ }^{43}$ Thus, employment loss might exacerbate the experience of food insecurity but maintaining employment is not completely preventative. This may be especially true for students who report a disability, are in their upper-class academic years and are first-generation students, which were student populations associated with being food insecure in this study. Accordingly, as the \#RealCollege Report suggests, food insecurity is likely associated with more than a temporary loss of income which college administrators need to consider when making decisions regarding COVID-19. ${ }^{43}$

The US Department of Agriculture chief economist discussed the rise in food cost because of the impacts of COVID-19 on the food supply chain. ${ }^{44}$ As a result, many Americans' grocery expenditures increased during COVID-19. Authors in this study found that newly food insecure students had increased expenditures on groceries since COVID-19. The nationwide campus closures forced many students living on campus to relocate, which did not guarantee increased access to food ${ }^{28}$ as many experienced decreased access to paid resources such as housing and dining. ${ }^{26}$ In addition, students lost access to community resources such as food pantries and were ineligible for federal benefits, including Supplemental Nutrition Assistance Program, ${ }^{45}$ at the time of this study despite requests to waive eligibility restrictions during the early days of the pandemic. Therefore, students who were financially independent and are more likely to be food insecure $^{23}$ also had to budget for higher-priced items. Altogether, the ineligibility of pandemic aid, and the loss of campus resources and meal plans likely resulted in many students having to purchase food at grocery stores, which could explain our findings that newly food insecure students experienced the loss of access to food resources and had increased expenditures on groceries.

Although students were 58\% more likely to be newly food insecure if they had increased grocery expenditure since COVID-19, newly foodinsecure students reported eating less since the start of the pandemic. These results are similar to Owens and colleagues ${ }^{25}$ in which $46.2 \%$ of respondents said they eat less because there was not enough food or money. Taken together, newly food-insecure students maybe be spending more but not be buying nutritionally dense foods or foods that last potentially because of the limited knowledge of grocery shopping, cooking skills, and nutrition literacy among food-insecure students. $^{23,46}$

In addition, eating patterns are influenced by emotional responses, including anxiety, depression, worry, and stress which were found to be key determinants in food consumption during COVID-19 in Italy. ${ }^{47,48}$ Studies suggest that mental health and emotional responses, including anxiety, depression, worry, perceived threat, and stress, are increased when experiencing public health emergencies or epidemics. ${ }^{49-51}$ Furthermore, studies have reported increased anxiety, threat, and depression among college students during the COVID$19 .^{26,49,52-54}$ In this study, depression and anxiety were associated with student food security status. The relationship between mental health and food insecurity is considered bidirectional, with previous research that indicating that severe depression can influence the onset of food insecurity. ${ }^{55}$ In this study, severe anxiety significantly predicted a student becoming newly food secure. This finding may relate to a student's anxiety during COVID-19 as students who perceived COVID-19 to be a severe threat to themselves were also $120 \%$ more likely to be newly food insecure. The perceived threat of COVID-19 varies among college students depends on many variables, including age, education and knowledge, media exposure, perceived severity of COVID-19, contraction of COVID-19, and mental health. ${ }^{56-58}$ Research has shown that students who perceived COVID-19 as a severe threat were more likely to have sufficient and correct knowledge about masking wearing, susceptible populations, symptoms of infection, hand washing, and preventative measures. ${ }^{57}$ Therefore, those in this study who perceived COVID-19 as a severe threat may have had anxiety visiting the grocery shopping and instead taken grocery store precautions, which can lead to more expensive measures, such as purchasing a 2-week to 30 day supply of food or using delivery and/or curbside pickup. ${ }^{59}$

Although this study highlights the potential impact of COVID-19 on student food security status and factors associated with becoming newly food insecure, this study is not without limitations. The use of cross-sectional data cannot infer causality. In addition, the response rate was low, and the sample cannot be generalized to the college population. At West Virginia University, the student population is $79.1 \%$ White, $53.6 \%$ male, and $52 \%$ are residents of the state. ${ }^{60}$ The national college population is $55.2 \%$ White and $55.5 \%$ female. ${ }^{61}$ Thus, comparatively, the sample in this study had a higher proportion of respondents that were White and female. Although West Virginia University does not provide a breakdown of the student population by all school years, the main campus had 26,839 students enrolled, with 21,086 undergraduates, 4,821 in the freshman class, 1,490 
professional students, 4,263 graduate students, and 1,864 international students. ${ }^{62}$ The sample in this study had a $29.6 \%$ completion rate among graduate and professional students, which is higher than the university population suggests. In addition, national student statistics suggest that first-generation college students make up a third of the student body, which is similar to the demographics shown here. $^{63}$ Similarly, national disability statistics suggest an estimated 20\% of undergraduates and $12 \%$ of the postbaccalaureate report having a disability, which our sample does not reflect. ${ }^{64}$ Therefore, our study population is not representative of our institution or college students nationally.

Furthermore, the use of a 2-item food insecurity screener could have impacted the accuracy of the prevalence of food insecurity measured. Although the 2-item food insecurity screener is validated, ${ }^{39}$ and this screener has been used in previous college food insecurity research, ${ }^{40}$ testing its validity in college populations is limited, which is a commonly reported issue with food insecurity survey tools. ${ }^{65}$ Despite this, the level of food insecurity found within this study is similar to other research on college students, such as Owens et $\mathrm{al}^{25}$ reporting a $34.5 \%$ food insecurity rate compared with the $31.6 \%$ reported here during the COVID-19 pandemic. Regarding the change in food insecurity status, 2 research studies from the University of North Carolina-Chapel $\mathrm{Hill}^{27}$ and the University of Florida ${ }^{28}$ reported larger shifts in food insecurity than discussed in this study (20\% and $59.6 \%$, respectively, vs $15.1 \%$ ), although methodology for assessing change in food insecurity status varies across all studies. Thus, there is potential the use of the 2-item screener had lower sensitivity than longer survey methods, although future research is needed.

Finally, other factors that could have influenced a student becoming newly food insecure, such as a change in living situation, living with parents, the impact of COVID19 business restrictions, other indicators of financial status such as being financially dependent or independent and level of change in income, use of community resources, and knowledge of nutrition, were not collected in this study and may be of value to collect in future research.

\section{IMPLICATIONS FOR RESEARCH AND PRACTICE}

The COVID-19 pandemic has caused a major shift in the lives of college students across the US. College food insecurity was already an established public health issue plaguing campuses, and the COVID-19 pandemic has resulted in more students facing the burden of trying to access and afford food. As pointed out by Laska et $\mathrm{al}^{40}$ a multidisciplinary approach is needed to advocate for best practices to help these food-insecure students. It is essential that universities help students with COVID-19 related stressors and prioritize new approaches that support students in the hybrid-campus environment. A potential way to lessen food insecurity among college students is to maintain campus jobs and keep dining options open with take-out or delivery options. In addition, many college students have low nutrition literacy, food purchasing, and cooking skills. Therefore, first-year seminars, both online and in-person, that incorporate components of nutrition education, including food budgeting, recipes, and nutrition, are encouraged to assist students in understanding ways to appropriately manage money expenditure and healthy eating. Online educational modules can be developed and freely available to students to seek to achieve nutrition literacy.

Furthermore, higher education intuitions would benefit by continuing access to mental health services in a variety of environments (ie, online and group counseling) and incorporating more comprehensive services that support and encourage healthy eating patterns and purchasing. Additional outreach and resources are needed for first-generation or newly and consistently food-insecure students with disabilities. University counseling, health, and outreach centers can increase their efforts to reach at-risk students with health messaging to share coping strategies, skills, and resources available during campus shutdowns. Finally, college administration and policymakers are urged to consider investing in student emergency aid and lobbying for increased aid for college students during COVID-19. Thus, college administrators, nutrition educators, stakeholders, and policymakers may use the evidence in this study to support the claim that more students are facing food insecurity as a result of the COVID-19 pandemic. Future research can expand on these findings, with the potential for qualitative research to gain further insight into the barriers students have faced during the COVID-19 pandemic.

\section{ACKNOWLEDGMENTS}

Primary funding is from the West Virginia Agricultural and Forestry Experiment Station WVA00689 and WVA00721.

\section{SUPPLEMENTARY DATA}

Supplementary data related to this article can be found at https://doi. org/10.1016/j.jneb.2021.08.010.

\section{REFERENCES}

1. Coleman-Jensen A, Rabbitt MP, Gregory CA, Singh A. Household Food Security in the United States in 2018. USDA, Economic Research Service; 2019. https://www.ers.usda.gov/webdocs/ publications/94849/err-270.pdf? $\mathrm{v}=8083.4$. Accessed December 30, 2020.

2. Campbell CC. Food insecurity: a nutritional outcome or a predictor variable? J Nutr. 1991;121:408-415.

3. Paslakis G, Dimitropoulos G, Katzman DK. A call to action to address COVID19-induced global food insecurity to prevent hunger, malnutrition, and eating pathology. Nutr Rev. 2021;79:114-116.

4. Koo JR, Cook AR, Park M, et al. Interventions to mitigate early spread of SARS-CoV-2 in Singapore: a modelling study. Lancet Infect Dis. 2020;20: 678-688.

5. Niles MT, Bertmann F, Belarmino EH, Wentworth T, Biehl E, Neff R. The early food insecurity impacts of COVID-19. Nutrients. 2020;12:2096.

6. Gundersen C, Hake M, Dewey A, Engelhard E. Food insecurity during COVID-19. Appl Econ Perspect Policy. 2021;43:153-161. 
7. Kozicki B, Gornikiewicz M. Unemployment rate in Poland and USA during COVID-19 pandemic: a case study. Eur Res Stud. 2020;23:187-201.

8. McElvaine RS. The Great Depression: America, 1929-1941. Broadway Books; 1993.

9. Hake M, Engelhard E, Dewey A, Gundersen C. The Impact of the Coronavirus on Child Food Insecurity. Feeding America; 2020. https://www.feedingamerica.org/ sites/default/files/2020-04/Brief_Impact $\% 20$ of $\% 20$ Covid $\% 20$ on $\% 20$ Child \%20Food\%20Insecurity\%204.22.20.pdf. Accessed October 1, 2020.

10. Food and Agriculture Organization. An Introduction to the Basic Concepts of Food Security. EC-FAO Food Security Programme; 2008. http://www.fao.org/3/ al936e/al936e.pdf. Accessed October 1, 2020.

11. Torero M. Without food, there can be no exit from the pandemic. Nature. 2020;580:588-589.

12. Holland K. Canada's Food Security During the COVID-19 Pandemic. The School of Public Policy Publications; 2020. https:// ssrn. $\mathrm{com} / \mathrm{abstract}=3625271$. Accessed July 1, 2021.

13. Leung CW, Epel ES, Ritchie LD, Crawford PB, Laraia BA. Food insecurity is inversely associated with diet quality of lower-income adults. J Acad Nutr Diet. 2014;114:1943-1953.e2.

14. Davison KM, Gondara L, Kaplan BJ. Food insecurity, poor diet quality, and suboptimal intakes of folate and iron are independently associated with perceived mental health in Canadian adults. Nutrients. 2017;9:274.

15. Meza A, Altman E, Martinez S, Leung CW. "It's a Feeling That One Is Not Worth Food": a qualitative study exploring the psychosocial experience and academic consequences of food insecurity among college students. $J$ Acad Nutr Diet. 2019;119:1713-1721. e1.

16. Heflin C, Kukla-Acevedob S, Darolia R. Adolescent food insecurity and risky behaviors and mental health during the transition to adulthood. Child Youth Serv Rev. 2019;105:104416.

17. Pryor L, Lioret S, Van Der Waerden J, Fombonne É, Falissard B, Melchior M. Food insecurity and mental health problems among a community sample of young adults. Soc Psychiatry Psychiatr Epidemiol. 2016;51:1073-1081.

18. Nikolaus CJ, An R, Ellison B, NickolsRichardson SM. Food insecurity among college students in the United States: a scoping review. $A d v$ Nutr. 2020;11:327-348

19. McArthur LH, Ball L, Danek AC, Holbert D. A high prevalence of food insecurity among university students in Appalachia reflects a need for educational interventions and policy advocacy. J Nutr Educ Behav. 2018;50:564572.

20. Hagedorn RL, McArthur LH, Hood LB, et al. Expenditure, coping, and academic behaviors among food-insecure college students at 10 higher education institutes in the Appalachian and Southeastern regions. Curr Dev Nutr. 2019;3:nzz058.

21. Hagedorn RL, Olfert MD. Food insecurity and behavioral characteristics for academic success in young adults attending an Appalachian University. Nutrients. 2018;10:361.

22. Hege A, Stephenson T, Pennell M, et al. College food insecurity: implications on student success and applications for future practice. $J$ Student Aff Res Pract. 2021;58:44-61.

23. Gaines A, Robb Clifford A, Knol Linda, Sicker S. Examining the role of financial factors, resources and skills in predicting food security status among college students. Int J Consum Stud. 2014;38:374-384.

24. Hagedorn RL, Olfert MD, MacNell L, et al. College student sleep quality and mental and physical health are associated with food insecurity in a multicampus study. Public Health Nutr. 2021;24:4305-4312.

25. Owens MR, Brito-Silva F, Kirkland T, et al. Prevalence and social determinants of food insecurity among college students during the COVID-19 pandemic. Nutrients. 2020;12:2515.

26. Hagedorn RL, Wattick RA, Olfert MD. "My Entire World Stopped": college students' psychosocial and academic frustrations during the COVID19 pandemic [published online ahead of print May 11, 2021]. Appl Res Qual Life. https://doi.org/10.1007/s11482021-09948-0.

27. Soldavini J, Andrew $H$, Berner $M$. Characteristics associated with changes in food security status among college students during the COVID-19 pandemic. Transl Behav Med. 2021;11:295304.

28. Mialki K, House LA, Mathews AE, Shelnutt KP. COVID-19 and college students: food security status before and after the onset of a pandemic. Nutrients. 2021;13:628.

29. Dillman DA, Smyth JD, Christian LM. Internet, Phone, Mail, and Mixed-mode Surveys: The Tailored Design Method. John Wiley \& Sons; 2014.

30. Larin K. Food Insecurity: Better Information Could Help Eligible College Students Access Federal Food Assistance Benefits. US Government Accountability Office; 2018. https://www.gao.gov/assets/gao-19-95. pdf. Accessed October 1, 2020.

31. El Zein A, Shelnutt KP, Colby S, et al. Prevalence and correlates of food insecurity among US college students: a multi-institutional study. BMC Public Health. 2019;19:660.

32. Payne-Sturges DC, Tjaden A, Caldeira KM, Vincent KB, Arria AM. Student hunger on campus: food insecurity among college students and implications for academic institutions. Am J Health Promot. 2018;32:349-354.

33. Haskett ME, Majumder S, KotterGrühn D, Gutierrez I. The role of university students' wellness in links between homelessness, food insecurity, and academic success. J Soc Distress Homeless. 2021;30:59-65.

34. Phillips E, McDaniel A, Croft A. Food insecurity and academic disruption among college students. J Stud Aff Res Pract. 2018;55:353-372.

35. Patton-Lopez MM, Lopez-Cevallos DF, Cancel-Tirado DI, Vazquez L. Prevalence and correlates of food insecurity among students attending a midsize rural university in Oregon. J Nutr Educ Behav. 2014;46:209-214.

36. Kroenke K, Spitzer RL, Williams JB. The PHQ-9: validity of a brief depression severity measure. J Gen Intern Med. 2001;16:606-613.

37. Spitzer RL, Kroenke K, Williams JB, Löwe B. A brief measure for assessing generalized anxiety disorder: the GAD7. Arch Intern Med. 2006;166:10921097.

38. US Department of Agriculture, Economic Research Service. U.S. Adult Food Security Survey Module: three-stage design, with screeners. US Department of Agriculture, Economic Research Service; 2012. https://www.ers.usda.gov/ media/8279/ad2012.pdf. Accessed June 15, 2020.

39. Hager ER, Quigg AM, Black MM, et al. Development and validity of a 2item screen to identify families at risk for food insecurity. Pediatrics. 2010;126: e26-e32. 
40. Laska MN, Lenk K, Lust K, McGuire CM, Porta CM, Stebleton M. Sociodemographic and health disparities among students screening positive for food insecurity: findings from a large college health surveillance system. Prev Med Rep. 2021;21:101297.

41. Bursac Z, Gauss CH, Williams DK, Hosmer DW. Purposeful selection of variables in logistic regression. Source Code Biol Med. 2008;3:17.

42. US Bureau of Labor Statistics. Labor force statistics from the current population survey. https://www.bls.gov/web/ empsit/cpseea10.htm. Accessed July 20, 2021.

43. Goldrick-Rab S, Coca V, Kienzl G, Welton CR, Dahl S, Magnelia S. \#RealCollege during the pandemic: new evidence on basic needs insecurity and student well-being. https://hope4college.com/ realcollege-during-the-pandemic/. Accessed December 30, 2020.

44. Johansson R. Another look at availability and prices of food amid the COVID-19 pandemic. https://www.usda.gov/ media/blog/2020/05/28/another-lookavailability-and-prices-food-amidCOVID-19-pandemic. Accessed July 30, 2021

45. Laska MN, Fleischhacker S, Petsoulis C, Bruening M, Stebleton MJ. Addressing college food insecurity: an assessment of federal legislation before and during coronavirus disease-2019. J Nutr Educ Behav. 2020;52:982-987.

46. Begley A, Paynter E, Butcher LM, Dhaliwal SS. Examining the association between food literacy and food insecurity. Nutrients. 2019;11:445.

47. Di Renzo L, Gualtieri P, Cinelli G, et al. Psychological aspects and eating habits during COVID-19 home confinement: results of EHLC-COVID-19 Italian online survey. Nutrients. 2020; 12:2152

48. Di Renzo L, Gualtieri P, Pivari F, et al. Eating habits and lifestyle changes during COVID-19 lockdown: an Italian survey. J Transl Med. 2020;18:1-15.

49. Wang ZH, Yang HL, Yang YQ, et al. Prevalence of anxiety and depression symptom, and the demands for psychological knowledge and interventions in college students during COVID-19 epidemic: a large cross-sectional study. $J$ Affect Disord. 2020;275:188-193.

50. Lau JT, Yang X, Tsui H, Pang E, Wing YK. Positive mental health-related impacts of the SARS epidemic on the general public in Hong Kong and their associations with other negative impacts. J Infect. 2006;53:114-124.

51. Jalloh MF, Li W, Bunnell RE, et al. Impact of Ebola experiences and risk perceptions on mental health in Sierra Leone, July 2015. BMJ Global Health. 2018;3:e000471.

52. Zhai Y, Du X. Addressing collegiate mental health amid COVID-19 pandemic. Psychiatry Res. 2020;288:113003.

53. Husky MM, Kovess-Masfety V, Swendsen JD. Stress and anxiety among university students in France during COVID-19 mandatory confinement. Compr Psychiatry. 2020;102:152191.

54. Chang J, Yuan Y, Wang D. [Mental health status and its influencing factors among college students during the epidemic of COVID-19]. Nan Fang Yi Ke Da Xиe Хиe Bao. 2020;40:171-176.

55. Maynard M, Andrade L, Packull-McCormick S, Perlman CM, Leos-Toro C, Kirkpatrick SI. Food insecurity and mental health among females in highincome countries. Int J Environ Res Public Health. 2018;15:1424.

56. Li X, Lv S, Liu L, et al. COVID-19 in Guangdong: immediate perceptions and psychological impact on 304,167 college students. Front Psychol. 2020; 11:2024.

57. Ding Y, Du X, Li Q, et al. Risk perception of coronavirus disease 2019 (COVID-19) and its related factors among college students in China during quarantine. PLoS One. 2020;15: e0237626.

58. Gao J, Zheng P, Jia Y, et al. Mental health problems and social media exposure during COVID-19 outbreak. PLoS One. 2020;15:e231924.

59. Martin-Neuninger R, Ruby MB. What does food retail research tell us about the implications of Coronavirus (COVID-19) for grocery purchasing habits? Front Psychol. 2020;11:1448.

60. Consumer Information at West Virginia University. WVU Morgantown student body diversity. https:// consumerinformation.wvu.edu/wvu-morgantown-student-body-diversity. Accessed May 4, 2021.

61. National Center for Education Statistics. College enrollment rates. https://nces. ed.gov/programs/coe/indicator_cpb.asp. Accessed July 1, 2021.

62. West Virginia University. How many students are enrolled? West Virginia University. https://www.wvu.edu/faq/howmany-students-are-enrolled. Accessed May 4, 2021.

63. Center for First Generation Student Success. National Data Fact Sheets on First-Generation College Students. https://firstgen.naspa.org/journal-andresearch/national-data-fact-sheets-onfirst-generation-college-students / national-data-fact-sheets. Accessed July 1, 2021.

64. National Center for Education Statastics. Students with disabilities. https:// nces.ed.gov/fastfacts/display.asp? $\mathrm{id}=60$ Date accessed: July 1, 2021.

65. Nikolaus CJ, Ellison B, Nickols-Richardson SM. Are estimates of food insecurity among college students accurate? Comparison of assessment protocols. PLoS One. 2019;14:e0215161.

\section{ORCID}

Melissa D. Olfert: http://orcid.org/ 0000-0002-6686-3891 